\title{
Differential contribution of tissue factor and Factor XII to thrombin generation triggered by breast and pancreatic cancer cells
}

\author{
AURÉLIE ROUSSEAU ${ }^{1,2}$, ANNETTE K. LARSEN ${ }^{1}$, PATRICK VAN DREDEN ${ }^{2}$, \\ MICHELE SABBAH $^{1}$, ISMAIL ELALAMY ${ }^{1,3}$ and GRIGORIS T. GEROTZIAFAS ${ }^{1,3}$
}

${ }^{1}$ Cancer Biology and Therapeutics, Centre de Recherche Saint-Antoine, INSERM U938, Institut Universitaire de Cancérologie, Faculty of Medicine Pierre and Marie Curie (UPMC), Sorbonne Universities, Paris; ${ }^{2}$ Clinical Research,

Diagnostica Stago, Gennevilliers; ${ }^{3}$ Department of Biological Hematology, Tenon Hospital,

University Hospitals of the East Paris, Paris, France

Received April 27, 2017; Accepted May 10, 2017

DOI: 10.3892/ijo.2017.4172

\begin{abstract}
Most cancer cells trigger thrombin generation (TG) to various extent. In the present study, we dissected the mechanisms responsible for the procoagulant activity of pancreatic adenocarcinoma cells (BXPC3), a highly thrombogenic cancer type, and breast cancer cells (MCF7), a less thombogenic tumor type. TG of normal plasma was assessed by the Thrombinoscope $\left(\mathrm{CAT}^{\circledR}\right)$ in the presence or absence of cancer cells. TG was also assessed in plasma depleted of clotting factors, in plasma spiked with tissue factor (TF) and/or procoagulant phospholipids, in plasma spiked with an anti-TF monoclonal antibody or with corn trypsin inhibitor (CTI). The presence of alternatively spliced TF (asTF), TF activity ( $\mathrm{TFa}$ ) and cancer procoagulant (CP) levels were determined. TFa and asTF were highly expressed by BXPC3 cells, compared to MCF7 cells, while CP levels were higher
\end{abstract}

Correspondence to: Dr Grigoris T. Gerotziafas, Department of Biological Hematology, Tenon Hospital, University Hospitals of the East Paris, Paris, France

E-mail: grigorios.gerotziafas@aphp.fr

Abbreviations: VTE, venous thromboembolism; TF, tissue factor; CP, cancer procoagulant; MCF7, Michigan Cancer Foundation 7 human breast cancer cells; BXPC3, human pancreatic adenocarcinoma cells; FVII, coagulation factor VII; FXII, coagulation factor XII; FXI: coagulation factor XI; FIX, coagulation factor IX; FVIII, coagulation factor VIII; FX, coagulation factor X; FV, coagulation factor V; FII: coagulation factor II; TFa, tissue factor activity; asTF, alternatively spliced TF; RVV, Russell's viper venom; PPP, platelet poor plasma; MRI, mean rate index; HUVECs, primary human umbilical vein endothelial cells; CTI, corn trypsin inhibitor; TG, thrombin generation; UNL, upper normal limit; ttPeak, time to peak; PPL, procoagulant phospholipids

Key words: cancer, thrombin generation, hypercoagulability, tissue factor, factor XII in MCF7 cells. BXPC3 cells had a stronger effect on TG than MCF7 cells. Accordingly, anti-TF had more inhibitory activity on TG triggered by BXPC 3 cells while CTI had more pronounced inhibitory effect on TG triggered by MCF7 cells. TG enhancement by both BXPC3 and MCF7 cells was mediated by FVII and intrinsic tenase while FXII and FXI were also important for MCF7 cells. The induction of TG by BXPC 3 cells was mainly driven by the TF pathway while TG generation triggered by MCF7 cells was also driven by FXII activation. Therefore, hypercoagulability results from a combination of the inherent procoagulant properties of cancer cell-associated TF as well as of procoagulant phospholipids in the plasma microenvironment.

\section{Introduction}

Blood hypercoagulability is common in cancer patients (1-3) with different risk of venous thromboembolism (VTE) according to cancer type (4-6). Cancer cells are directly involved in the pathogenesis of thrombosis through the induction and amplification of thrombin generation $(7,8)$. According to the cell-based model of blood coagulation, triggering of thrombin generation occurs by direct contact of tissue factor (TF)-expressing cells with plasma factors VII (FVII) and VIIa (FVIIa) which is amplified in the presence of procoagulant phospholipids (PPL) provided by cell-derived microparticles (9-11). The TF/FVIIa complex generates activated factor X (FXa) that induces the initial generation of trace amounts of thrombin leading to activation of platelets, factor $\mathrm{V}(\mathrm{FV})$ and factor VIII (FVIII). In the presence of ionized calcium, intrinsic tenase (FIXa/FVIIIa/procoagulant phospholipids) and prothrombinase ( $\mathrm{FXa} / \mathrm{FVa}$ /procoagulant phospholipids) lead to a burst of thrombin generation (12-14). An alternative pathway of thrombin generation involves activation of the contact system through FXII activation $(15,16)$. The contact system is usually considered less important than the TF-pathway, but has attracted recent interest, especially in the context of cancerinduced hypercoagulability $(17,18)$. Finally, some cancer cells express the cancer procoagulant $(\mathrm{CP})$ factor, a $68 \mathrm{kDa}$ protease 
that directly activates FX, which represents an additional pathway of cancer-induced hypercoagulability $(19,20)$.

We have recently shown that exposure of human plasma to pancreatic adenocarcinoma (BXPC3) or breast cancer cells (MCF7) can enhance thrombin generation (21). Of note, these findings are not restricted to cells from solid tumors since Marchetti at al reported that cells from hematological malignancies may also enhance thrombin generation (22). We herein characterize the mechanisms by which cancer cells trigger blood coagulation using an original and validated experimental system, to elucidate the role of the TF-pathway and the intrinsic clotting system in thrombin generation. It is widely accepted that the plasma microenvironment plays a key role in hypercoagulability. Therefore, thrombin generation was assessed under different experimental conditions with respect to the concentration of TF and procoagulant phospholipids in the plasma as well as in plasma selectively deficient in factor VII (FVII), factor XII (FXII), factor XI (FXI), factor IX (FIX), factor VIII (FVIII), factor X (FX), factor V (FV) and factor II (FII). We finally determined the amounts of TF released by cancer cells in their local microenvironment.

\section{Materials and methods}

Cell cultures. Different histological types of cancer cells derived from pancreatic cancer (BXPC3), breast cancer (MDA-MB231, MCF7, BT20), colon cancer (HT29, HCT-116) and ovarian cancer (IGROV1) were characterized with respect to thrombin generation in human plasma. We then selected two cells lines, MCF-7 and BXPC3, with different capacity for thrombin generation. Both cell lines are typical of their cancer origin, since pancreatic cancer is known for its strong thromobogenic potential whereas the thrombogenic potential of breast cancer is less prominent. BXPC3, a human pancreatic adenocarcinoma cell line and MCF7 breast adenocarcinoma cell line were obtained from American Type Culture Collection (ATCC, Rockville, MD, USA).

Cells were expanded and cultured as described elsewhere (21). A volume of $100 \mu \mathrm{l}$ cell suspension (50 cells $/ \mu \mathrm{l}$ ) was placed in 96-well plates and cells were incubated for $24 \mathrm{~h}$ at $37^{\circ} \mathrm{C}$ in a $100 \%$ humidified atmosphere with $5 \% \mathrm{CO}_{2}$. After $24 \mathrm{~h}$ incubation, BXPC3 cells reached $70 \%$ confluence and MCF7 cells $80 \%$ confluence. Under these conditions, the two cancer cell lines induced similar levels of thrombin generation. To rule out any potential interference of the trypsin used to detach the cells on thrombin generation, we compared thrombin generation for cells that has been detached mechanically or by exposure to trypsin. We also confirmed that the concentration of fetal bovine serum (ranging from $1 \%$ to $10 \%$ ) and the incubation time (ranging from 5 to $72 \mathrm{~h}$ ) did not significantly influence the procoagulant potential as determined by thrombin generation. For the studied cancer cell lines, a plateau effect on thrombin generation was observed at cell numbers higher than 50 cells $/ \mu 1$. Cells were only used if the apoptotic fraction was inferior to $2 \%$.

Primary human umbilical vein cells (HUVECs) were used to represent normal human cells. HUVECs were obtained from Clonetics (San Diego, CA, USA) and cultured in endothelial cell growth media EGM-2 (Clonetics) containing 2\% fetal bovine serum and supplements. Cells of 2 nd passage were used for the experiments. Cells were cultured in $25 \mathrm{~cm}^{2}$ culture flasks at $37^{\circ} \mathrm{C}$ in a $100 \%$ humidified atmosphere with $5 \% \mathrm{CO}_{2}$. Cells were used for experiments at a confluence of $80 \%$. For thrombin generation, the same experimental protocol was used for the HUVECs (50 cells/ $\mu \mathrm{l}$ ) as described above for BXPC3 and MCF7 cells.

Normal human plasma. Platelet-poor plasma (PPP) for thrombin generation experiments was purchased from Diagnostica Stago, Gennevilliers, France (ref. 00539). Plasma samples for thrombin generation experiments in plateletrich plasma (PRP) were obtained from healthy volunteers, members of the laboratory staff, who had not taken any medication during the previous 30 days. Blood samples were taken by atraumatic antecubital venipuncture and collected in siliconized vacutainer tubes (Becton Dickinson, Meylan, France) containing buffered $0.13 \mathrm{M}$ trisodium citrate (nine parts blood to one part citrate solution, 3.8\%). Platelet-rich plasma was prepared after centrifugation of citrated whole blood for $10 \mathrm{~min}$ at $150 \mathrm{x} \mathrm{g}$ at room temperature. After centrifugation, the supernatant PRP was removed and the platelet count was adjusted to $150 \times 10^{9} / 1$ by dilution with autologous PPP obtained after a further centrifugation of the remaining blood for $15 \mathrm{~min}$ at $2,000 \times \mathrm{g}$.

Specific TF activity and concentration of alternatively spliced TF. BXPC3 and MCF7 cells were washed three times in PBS, suspended in distilled water (at a final concentrations of 50 to 200 cells $/ \mu \mathrm{l}$ ) and incubated at $4^{\circ} \mathrm{C}$ for $30 \mathrm{~min}$. Then, samples were centrifuged for $30 \mathrm{~min}$ at $1000 \mathrm{x} \mathrm{g}$, supernatants were collected and kept frozen at $-80^{\circ} \mathrm{C}$ until measurements of TF activity.

Tissue factor activity (TFa) was measured in the absence or presence of cells with the same normal plasma as used for thrombin generation. Tissue factor activity was assessed with an in-house chromogenic method as described elsewhere (23-25). Alternatively spliced TF (asTF) was measured by a specific enzyme-linked immunosorbent assay (ELISA) as follows. The wells of a micro-ELISA plate were coated with an anti-asTF monoclonal antibody and the test samples, pre-diluted 1:1 with the sample dilution buffer, were added to the coated well. The asTF molecules, if present, will bind to the well. After a washing step to remove unbound material, a specific anti-human asTF peroxidase-conjugated monoclonal antibody was added. The anti-asTF peroxidase binds to the bound asTF. Following a washing step to remove excess anti-asTF peroxidase, the bound enzyme peroxidase was determined using the TMB substrate. Then, the color intensity was determined by spectrometry at $450 \mathrm{~nm}$.

Cancer procoagulant assay. The CP activity was determined using an in-house chromogenic assay. The activity of CP was evaluated by measuring the conversion of purified $\mathrm{FX}$ to $\mathrm{FXa}$ after incubation of cells in the presence of $\mathrm{CaCl}_{2}$ (50 $\mathrm{mmol} / 1$ in bis-Tris propane buffer, $\mathrm{pH}$ 6.7) for $30 \mathrm{~min}$ at $37^{\circ} \mathrm{C}$. Then, the FXa specific chromogenic substrate MAPAGly-Arg-pNA (CBS-0244 from Diagnostica Stago) was added and the amidolytic activity was measured. The kinetics of color development was recorded at $405 \mathrm{~nm}$ for $30 \mathrm{~min}$. The $\mathrm{CP}$ activity was expressed as $\mathrm{mUnits} / \mathrm{ml}(1 \mathrm{Unit}=$ the amount 
of enzyme needed to release $1 \mu \mathrm{mol}$ p-nitroanilide from the substrate in $1 \mathrm{~min}$ ). A calibration curve was constructed using increasing concentrations of Russell's viper venom (RVV); a serine proteinase that activates FX (from Diagnostica Stago). The RVV was used as the standard control to calibrate the assay. Thrombin formation is totally inhibited by incubation of cell extracts with $1 \mathrm{mmol} / 1 \mathrm{HgCL}_{2}$. Results are expressed as $\mathrm{mU} / \mathrm{mg}$ of protein. The specific cysteine proteinase inhibitor E64 (Sigma, St. Louis, MO, USA) was added to exclude possible non-specific interactions.

Calibrated automated thrombogram assay. In each well of the micro-plate, $80 \mu \mathrm{l}$ of PPP samples were mixed with saline (20 $\mu \mathrm{l})$. Thrombin generation was initiated by adding $20 \mu \mathrm{l}$ triggering solution containing $\mathrm{CaCl}_{2}$ (16.7 mM final concentration) and fluorogenic substrate (Z-Gly-Gly-Arg-AMC, $417 \mu \mathrm{M}$ final concentration). Thrombin generation was assessed with the Calibrated Automated Thrombogram assay (Thrombinoscope b.v., Maastricht, The Netherlands) as described elsewhere (26). Among thrombogram parameters we analyzed the mean rate index (MRI), which reflects the rate of the propagation phase of thrombin generation [calculated by the formula MRI = Peak / (ttPeak - lag-time) $]$. This parameter includes lag-time, the time to Peak (ttPeak) and the Peak. As previously shown, these parameters of the thrombogram, reflect the biological activity of cancer cells on thrombin generation better than the endogenous thrombin potential.

Procoagulant potential of cancer cells assessed with the calibrated automated thrombogram assay. BXPC3 cells, MCF7 cells or HUVECs were added to the wells of microtiter plates suitable for thrombin generation assessment. Then, $80 \mu \mathrm{l}$ of normal PPP were added to each well and thrombin generation was assessed as described above. For control experiments, the same procedure was used in the absence of cells. Each result represents several independent experiments as specified in the figure legends. In additional control experiments, thrombin generation was assessed in plasma spiked with increasing concentration of lymphocytes from healthy donors and was compared to thrombin generation obtained after calcification of normal plasma. No significant difference was found between the two experimental procedures (data not shown). In preliminary experiments, we also verified that the culture medium (containing RPMI, glutamine, penicillin, streptomycin and fetal calf serum) did not influence thrombin generation process of normal PPP. Thrombin generation was initiated and recorded as described above.

Thrombin generation in the presence of an anti-TF antibody. In separate experiments, $50 \mu \mathrm{l}$ of a working suspension of BXPC 3 or MCF7 cells (100 cells/ $\mu \mathrm{l})$ were mixed with an equal volume containing an anti-TF mouse monoclonal antibody 4509 (American Diagnostica, Neuville-sur-Oise, France) or a murine anti-human TF9-10H10 monoclonal antibody (AbD Serotec, Bio-Rad, Marnes-la-Coquette, France). Mouse IgG1 isotype $(100 \mu \mathrm{g} / \mathrm{ml})$ or saline were used in control experiments. Cells were incubated with the anti-TF antibody or the isotype $\mathrm{IgG} 1$ for $15 \mathrm{~min}$ at $37^{\circ} \mathrm{C}$ and $20 \mu \mathrm{l}$ of this suspension were mixed with $180 \mu \mathrm{l}$ of PPP at a final concentration of 5 cells $/ \mu 1$. The experimental conditions were defined after
Table I. Variability in the procoagulant activity of cancer cells on thrombin generation in normal human plasma.

\begin{tabular}{lrrcc}
\hline Cancer cell lines & $\begin{array}{c}\text { Lag-time } \\
(\mathrm{min})\end{array}$ & \multicolumn{1}{c}{$\begin{array}{c}\text { tt-Peak } \\
(\mathrm{min})\end{array}$} & $\begin{array}{c}\text { Peak } \\
(\mathrm{nM})\end{array}$ & $\begin{array}{c}\text { MRI } \\
(\mathrm{nM} / \mathrm{min})\end{array}$ \\
\hline MCF7 & $6.1 \pm 0.9$ & $9.6 \pm 1.1$ & $121 \pm 22$ & $34 \pm 6$ \\
MDA_MB-231 & $8.9 \pm 0.6$ & $14.5 \pm 0.8$ & $76 \pm 8$ & $14 \pm 3$ \\
BT20 & $2.3 \pm 0.4$ & $6.0 \pm 1.1$ & $129 \pm 6$ & $35 \pm 8$ \\
HT29 & $5.36 \pm 1.3$ & $11.8 \pm 1.9$ & $81 \pm 11$ & $13 \pm 4$ \\
HCT116 & $4.48 \pm 0.3$ & $9.9 \pm 0.5$ & $91 \pm 12$ & $17 \pm 3$ \\
IGROV1 & $2.5 \pm 1.4$ & $7.1 \pm 2.4$ & $95 \pm 10$ & $22 \pm 7$ \\
BXPC3 & $4.1 \pm 1.1$ & $6.9 \pm 1.3$ & $199 \pm 13$ & $71 \pm 7$ \\
Control & $9.6 \pm 1.2$ & $16.3 \pm 1.5$ & $118 \pm 9$ & $17 \pm 4$ \\
\hline
\end{tabular}

The control experiment consisted of recalcification of normal human platelet poor plasma (PPP) under cell-free conditions.

conducting preliminary experiments on thrombin generation, with variable concentrations of the cells and the anti-TF monocolonal antibody. Cells were used at the lower active concentration in plasma and antibody was employed at the concentration of $25 \mu \mathrm{g} / \mathrm{ml}$. At this concentration the anti-TF antibody completely inhibited the effect of high TF concentrations on thrombin generation. To eliminate any interactions of the phospholipid concentration, the impact of the anti-TF antibody on thrombin generation was carried out in normal PPP in the presence of MP-Reagent ${ }^{\circledR}$.

Impact of exogenous TF and phospholipids on the procoagulant potency of cancer cells. To evaluate the contribution of the microenvironment on the procoagulant potency of cancer cells, thrombin generation was assessed under the following experimental conditions: a) in the presence of optimal concentrations of TF (5 pM) and procoagulant phospholipids $(4 \mu \mathrm{M})$ using the PPP-Reagent $\left.{ }^{\circledR}(27), b\right)$ in the presence of 1 pM TF and $4 \mu \mathrm{M}$ procoagulant phospholipids (PPP-Reagent low), c) in the presence of $5 \mathrm{pM}$ TF without any addition of exogenous procoagulant phospholipids (PRP-Reagent), d) in the presence of $4 \mu \mathrm{M}$ of procoagulant phospholipids without any exogenous TF (MP-Reagent) and e) without any exogenous addition of TF and/or procoagulant phospholipids which represents the baseline thrombin generation triggered by cancer cells. For simplicity, the comparisons of thrombin generation produced under the different experimental systems were done on the basis of MRI, a parameter stemming from an equation that includes the other major parameters of thrombogram. The reagents PPP-Reagent, PRP-Reagent, MP-Reagent were purchased from Diagnostica Stago.

Thrombin generation after inhibition of the contact system of blood coagulation. To evaluate the impact of FXII activation by cancer cells, PPP spiked with $20 \mu \mathrm{g} / \mathrm{ml}$ of corn trypsin inhibitor (CTI, Merck Chemicals, Nottingham, UK) was incubated for $1 \mathrm{~h}$ at $37^{\circ} \mathrm{C}$. Then, PPP was added into the micro-plate wells containing BXPC3 and MCF7 cells and thrombin generation was assessed as described above. 

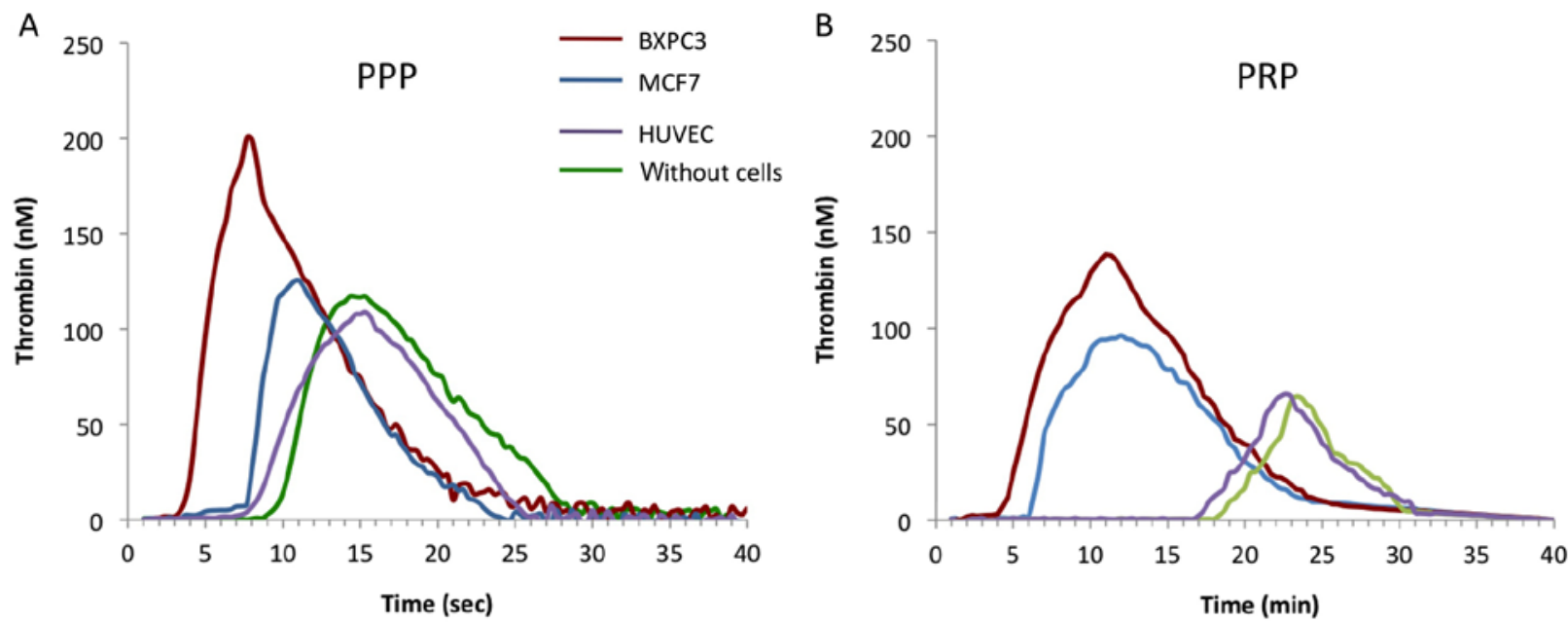

Figure 1. Representative thrombograms illustrating the effect of BXPC3 cells, MCF7 cells or HUVECs (50 cells/ $\mu$ l) on thrombin generation in normal platelet poor plasma (PPP) (A) or platelet-rich plasma (PRP) (B), compared to cell-free controls.

Table II. Levels of TFa and asTF in the supernatant of BXPC3 cells, MCF7 cells, HUVECs and in normal plasma.

\begin{tabular}{|c|c|c|c|c|c|c|c|}
\hline \multirow{2}{*}{$\begin{array}{l}\text { Tissue factor } \\
\text { levels }\end{array}$} & \multirow{2}{*}{$\begin{array}{c}\text { PPP } \\
\text { without cells }\end{array}$} & \multicolumn{3}{|c|}{50,000 cells $/ \mu 1$} & \multicolumn{3}{|c|}{200,000 cells $/ \mu 1$} \\
\hline & & HUVECs & BXPC3 & MCF7 & HUVEC & BXPC3 & MCF7 \\
\hline $\mathrm{TF}(\mathrm{pM})$ & $0.20 \pm 0.05$ & $0.23 \pm 0.02$ & $1.42 \pm 0.1^{\mathrm{a}, \mathrm{b}, \mathrm{c}}$ & $0.82 \pm 0.08^{\mathrm{a}, \mathrm{b}}$ & $0.26 \pm 0.02$ & $2.65 \pm 0.05^{\mathrm{a}, \mathrm{b}, \mathrm{c}}$ & $1.21 \pm 0.05^{\mathrm{a}, \mathrm{b}}$ \\
\hline asTF (ng/ml) & $0.02 \pm 0.01$ & $0.03 \pm 0.02$ & $0.35 \pm 0.09^{\mathrm{a}, \mathrm{b}, \mathrm{c}}$ & $0.05 \pm 0.02^{\mathrm{b}}$ & $0.04 \pm 0.01$ & $0.65 \pm 0.02^{\mathrm{a}, \mathrm{b}, \mathrm{c}}$ & $0.12 \pm 0.01^{\mathrm{a}, \mathrm{b}}$ \\
\hline
\end{tabular}

Values are the mean \pm SD of 5 independent experiments. ${ }^{a} \mathrm{p}<0.05$ vs. HUVEC, ${ }^{b} \mathrm{p}<0.05$ vs. platelet poor plasma (PPP) under cell-free conditions, ${ }^{\mathrm{c}} \mathrm{p}<0.05$ vs. MCF7.

Preliminary experiments showed that CTI concentrations equal or higher that $20 \mu \mathrm{g} / \mathrm{ml}$ significantly increased the lagtime as compared to the control. In contrast, no significant differences were observed at CTI concentrations higher than $20 \mu \mathrm{g} / \mathrm{ml}$. No significant differences of thrombin generation were found between plasma obtained from blood collected in tubes prefilled with CTI and with addition of CTI after plasma preparation (data not shown). To estimate the relative contribution of TF and contact system activation by cancer cells on thrombin generation, PPP spiked with $20 \mu \mathrm{g} / \mathrm{ml}$ of CTI and $25 \mu \mathrm{g} / \mathrm{ml}$ of anti-TF monoclonal antibody was incubated for $1 \mathrm{~h}$ at $37^{\circ} \mathrm{C}$.

Thrombin generation in clotting factor-deficient plasma. Immunodepleted lyophilised plasma deficient of clotting factors (FVII, FIX, FX, FII, FVIII, FXI, FXII) or protein C were from Diagnostica Stago. The clotting factor-deficient plasma was reconstituted according to the manufacturer's instructions. Clotting factor deficient plasma and normal PPP were added in the wells of the micro-plate containing cancer cells. Subsequently, thrombin generation was assessed as described above.

Statistical analysis. Non-parametric Mann-Withney test was applied to control changes in the thrombogram parameters in the presence or absence of cancer cells as well as in the different experimental condition described above. Results are shown as mean \pm SD. SPSS statistical software package was used for statistical analysis. The inhibition of thrombin generation (TG) was calculated by the formula inhibition of TG $=(1-$ TG cells $/$ TG control $) \%$. The upper normal limit (UNL) for each parameter of the thrombograms was defined for the control group as follows: $\mathrm{UNL}=$ mean $\pm 2 \mathrm{SD}$.

\section{Results}

Procoagulant activity of BXPC3 and MCF7 cells. Addition of cancer cells to normal PPP was accompanied by a significant increase of the Peak and MRI and a reduction of the lag-time and ttPeak compared to cell-free PPP (Table I). A similar effect was observed when the experiment was performed in PRP (Fig. 1A and B). We then selected two cells lines, MCF-7 and BXPC3, with different capacity for thrombin generation. Both cell lines are typical of their cancer of origin, since pancreatic cancer is known for its strong thromobogenic potential whereas the thrombogenic potential of breast cancer is less prominent. The two types of cancer cells had different influence on thrombin generation in normal human plasma. At equal cell number, MCF7 had less procoagulant activity than BXPC3 cells. In comparison, HUVECs had no significant influence on the parameters of the thrombogram compared to cell-free PPP or PRP (Fig. 1A and B). 
Table IV.Comparison of the expression of cancer pro-coagulant (CP) activity by MCF7 and BXPC3 cells.

\begin{tabular}{lcc}
\hline Cell lines & CP $(\mathrm{mU} / \mathrm{mg})$ & Inhibition by E64 $(\%)$ \\
\hline MCF7 & $220 \pm 35$ & 84 \\
BXPC3 & $60 \pm 15$ & 91
\end{tabular}

Based on these results, further studies were undertaken to elucidate the mechanistic basis for the hypercoagulability of BXPC3 and MCF7 cells.

Tissue factor expression by BXPC3 and MCF7 cells. Both BXPC3 and MCF7 cells expressed significantly higher TFa levels compared to normal plasma $(0.20 \pm 0.05 \mathrm{pM}, \mathrm{p}<0.05)$ and to HUVECs $(0.23 \pm 0.02 \mathrm{pM})$. However, BXPC3 expressed significantly higher TFa levels compared to MCF7 cells $(1.42 \pm 0.10 \mathrm{pM}$ vs. $0.82 \pm 0.08 \mathrm{pM}$, respectively, $\mathrm{p}<0.05)$. The levels of TFa increased with the number of cells (Table II). For all experimental conditions, the levels of TFa produced by BXPC3 cells were significantly higher than TFa expressed by the same number of MCF7 cells.

The levels of asTF were also significantly higher in the presence of BXPC3 or MCF7 cells compared to normal plasma $(0.02 \pm 0.01 \mathrm{ng} / \mathrm{ml} ; \mathrm{p}<0.05)$ or in the presence of HUVECs $(0.03 \pm 0.02 \mathrm{ng} / \mathrm{ml} ; \mathrm{p}<0.05)$. The levels of asTF were significantly increased in plasma incubated with BXPC3 cells compared to plasma incubated with MCF7 cells $(0.35 \pm 0.09 \mathrm{ng} / \mathrm{ml}$ vs. $0.05 \pm 0.02 \mathrm{ng} / \mathrm{ml}$, respectively; $\mathrm{p}<0.05)$ (Table II). For all concentrations of BXPC3 or MCF7 cells, the levels of asTF in plasma followed the concentrations of TFa.

Impact of anti-TF monoclonal antibodies on thrombin generation induced by BXPC3 and MCF7 cells. The addition of anti-TF monoclonal antibodies to PPP with BXPC3 or MCF7 cells significantly prolonged the lag-time and ttPeak and decreased the MRI and the Peak of thrombin generation compared to control experiments without anti-TF antibodies. Noteworthy, the relative inhibition of thrombin generation was higher for BXPC3 cells compared to MCF7 cells (Table III). In comparison, the anti-TF antibodies did not have a significant effect on thrombin generation in the presence of HUVECs.

Expression of cancer procoagulant activity by $B X P C 3$ and MCF7 cells. Both BXPC3 and MCF7 cells expressed cancer procoagulant activity, with MCF-7 cells expressing significantly higher activity compared to BXPC3 cells $(220 \pm 35 \mathrm{mU} / \mathrm{mg}$ vs. $60 \pm 15 \mathrm{mU} / \mathrm{mg}$, respectively; $\mathrm{p}<0.05)$. Addition of the cysteine protease inhibitor E64 resulted in significant inhibition of FXa activity in the presence of both BXPC3 (91\% inhibition) and MCF7 cells (84\% inhibition) (Table IV).

Influence of contact phase activation on thrombin generation triggered by $B X P C 3$ and MCF 7 cells. In the control experiment (PPP without cells) the addition of CTI (corn trypsin inhibitor) resulted in prolongation of the lag-time by $1.7 \pm 0.9$-fold, compared to that observed in the absence of CTI. In normal 


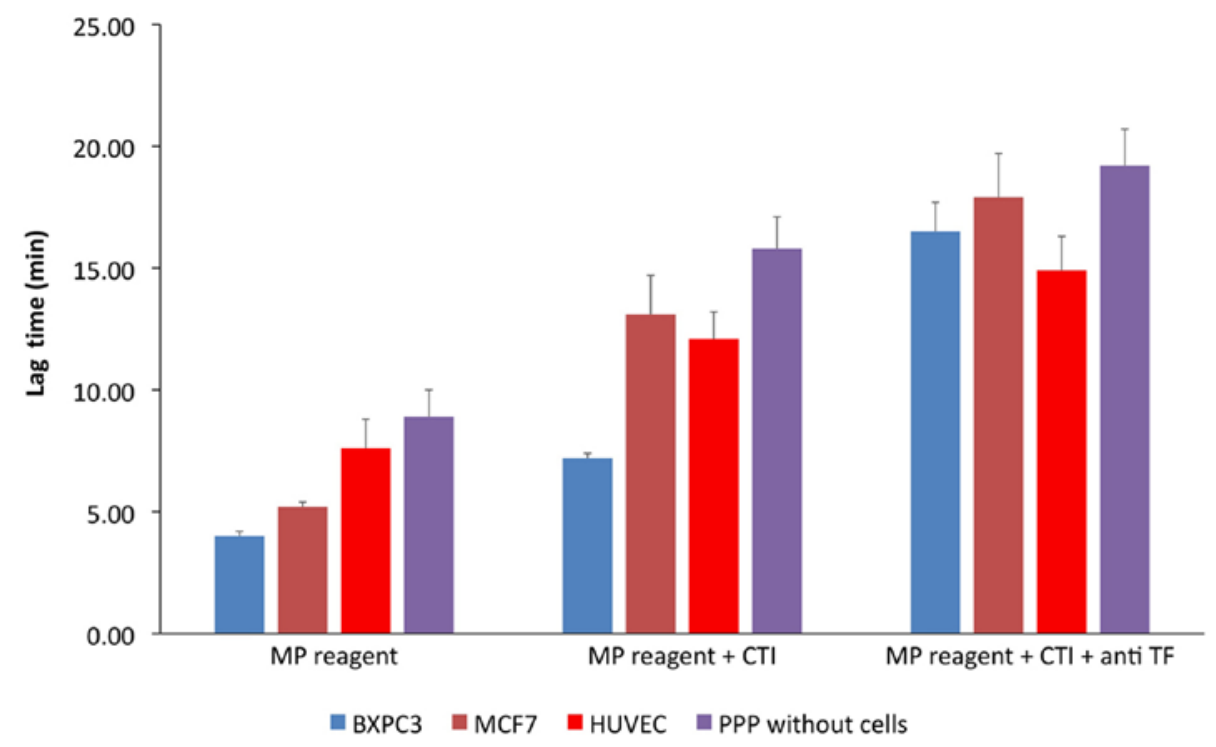

Figure 2. Variation of the lag-time in plasma after addition of corn trypsin inhibitor (CTI) and after addition of CTI and an anti-TF antibody (4509) in the presence of BXPC 3 cells, MCF7 cells or HUVECs. The results represent the mean \pm SD of 3 independent experiments. (MP reagent, PPL: $4 \mu \mathrm{M}$ ).

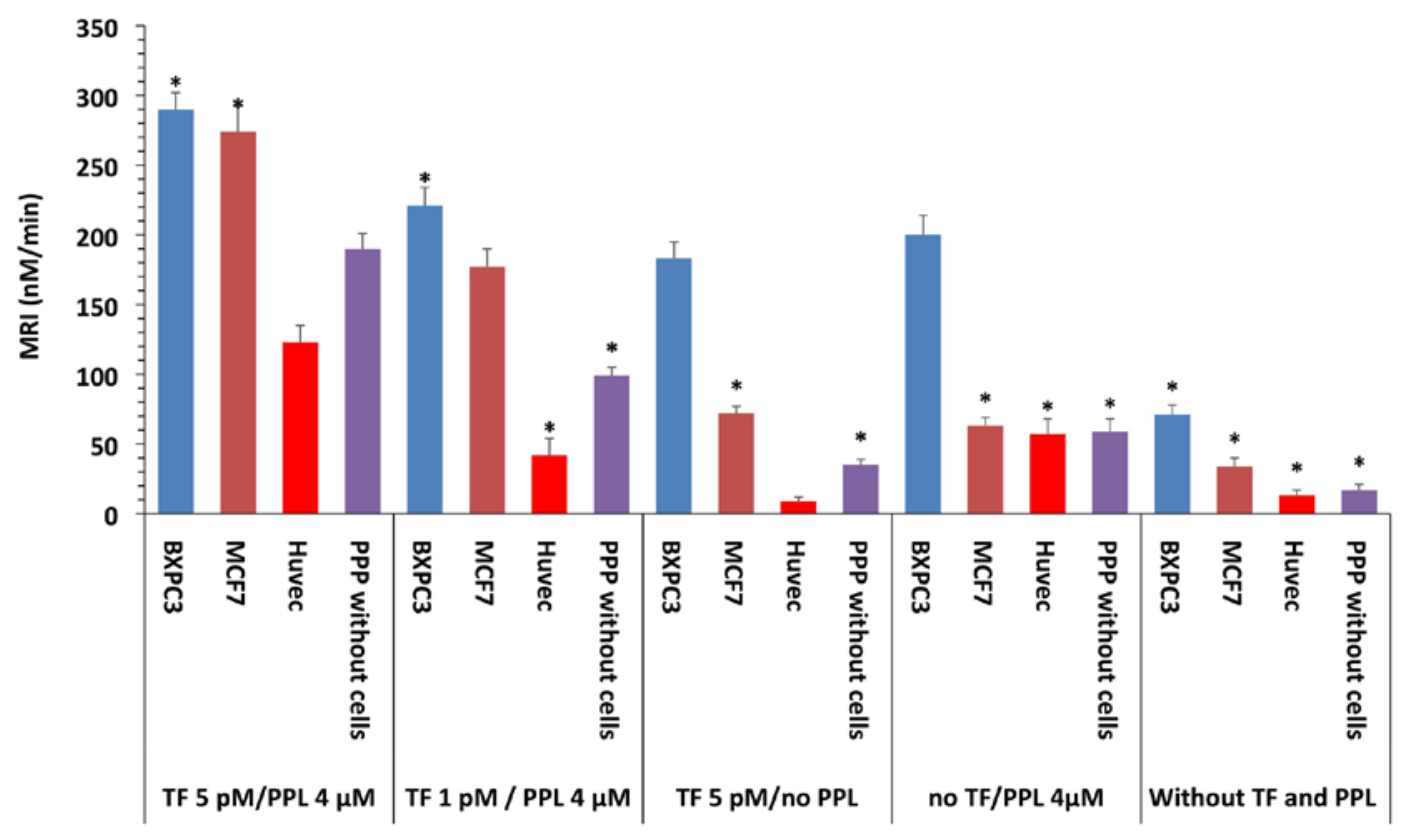

Figure 3. Alterations of the MRI in the presence of BXPC3 cells, MCF7 cells or HUVECs with the indicated concentrations of tissue factor (TF) and procoagulant phospholipids (PPL). The results represent the mean $\pm \mathrm{SD}$ of 8 independent experiments. ${ }^{*} \mathrm{p}<0.001$ vs. control in platelet poor plasma (PPP) reagent. TF 5 pM/PPL $4 \mu \mathrm{M})$.

PPP with BXPC3 or MCF7 cells, addition of CTI increased the lag-time by $1.8 \pm 1.3$-fold and $2.6 \pm 1.2$-fold, respectively, compared to the same experiment without CTI (Fig. 2). The increase of the lag-time induced by CTI was significantly less important in PPP with HUVECs (1.6 \pm 1.1 -fold). Concomitant addition of CTI and anti-TF increased the lag-time 2.3-fold in the presence of BXPC 3 cells, 1.3-fold in the presence of MCF7, 1.2-fold in the presence of HUVECs, and 1.2-fold in cell-free PPP.

Thrombin generation triggered by BXPC 3 and MCF7 cells in clotting factor-deficient plasma. The interaction of cancer cells with clotting factors was investigated by assessing thrombin generation in plasma deficient in specific clotting factors compared to normal plasma (control experiment). In the presence of BXPC3 or MCF7 cells, thrombin generation in plasma deficient for clotting factors VII, IX, XII, XI, and VIII was significantly reduced compared to normal plasma. Of note, the decrease of thrombin generation was different for each type of clotting factor-deficient plasma (Table V).

In FVII-deficient plasma, the lag-time increased 2.7-fold in the presence of BXPC 3 cells and 1.7-fold in the presence of MCF7 cells compared to normal PPP $(p<0.001)$. The peak and MRI decreased by 79 and $95 \%$, respectively, in the presence of 
Table V. Parameters of thrombin generation triggered with MP reagent by BXPC3 or MCF7 cells in the presence of in normal PPP and in plasma selectively depleted of the indicated clotting factors.

\begin{tabular}{|c|c|c|c|c|c|c|c|c|}
\hline \multirow[b]{2}{*}{ Parameters } & \multicolumn{2}{|c|}{ Lag-time (min) } & \multicolumn{2}{|c|}{ tt-Peak (min) } & \multicolumn{2}{|c|}{ Peak (nM) } & \multicolumn{2}{|c|}{ MRI (nM/min) } \\
\hline & ВXPC3 & MCF7 & BXPC3 & MCF7 & BXPC3 & MCF7 & BXPC3 & MCF7 \\
\hline Normal PPP & $4.0 \pm 0.6$ & $5.2 \pm 0.1$ & $5.9 \pm 1.2$ & $8.1 \pm 1.3$ & $320 \pm 12.6$ & $194 \pm 10$ & $188 \pm 7$ & $67 \pm 2$ \\
\hline FVII deficiency & $11.2 \pm 0.9^{\mathrm{b}}$ & $9.1 \pm 0.2^{\mathrm{b}}$ & $20.1 \pm 0.9^{b}$ & $11.2 \pm 1.2^{\mathrm{a}}$ & $66 \pm 11^{\mathrm{b}}$ & $79 \pm 9^{b}$ & $9 \pm 2^{b}$ & $37 \pm 3^{\mathrm{b}}$ \\
\hline FIX deficiency & $5.9 \pm 0.8^{\mathrm{a}}$ & $13 \pm 0.8^{b}$ & $12.2 \pm 2.0^{\mathrm{a}}$ & $12.1 \pm 1.3^{\mathrm{a}}$ & $70 \pm 12^{\mathrm{b}}$ & $15 \pm 2^{b}$ & $12 \pm 3^{b}$ & $2.3 \pm 4^{b}$ \\
\hline FXII deficiency & $11.2 \pm 0.2^{\mathrm{b}}$ & $8.3 \pm 1.5^{\mathrm{a}}$ & $14.3 \pm 0.8^{\mathrm{a}}$ & $16.3 \pm 1.4^{\mathrm{b}}$ & $192 \pm 8^{b}$ & $88 \pm 7^{b}$ & $64 \pm 8^{b}$ & $13 \pm 2^{b}$ \\
\hline FXI deficiency & $9.3 \pm 1.2^{\mathrm{b}}$ & $10.3 \pm 1.2^{\mathrm{b}}$ & $12.5 \pm 2.4^{\mathrm{a}}$ & $14.8 \pm 1.6^{\mathrm{b}}$ & $145 \pm 10^{\mathrm{b}}$ & $58 \pm 6^{b}$ & $48 \pm 3^{\mathrm{a}}$ & $14 \pm 5^{b}$ \\
\hline FVIII deficiency & $4.8 \pm 1.2$ & $5.1 \pm 0.9$ & $13.1 \pm 1.2^{\mathrm{a}}$ & $17.2 \pm 2.1^{\mathrm{b}}$ & $86 \pm 7^{\mathrm{b}}$ & $30 \pm 3^{b}$ & $11 \pm 6^{\mathrm{a}}$ & $2.8 \pm 3^{\mathrm{b}}$ \\
\hline PC deficiency & $3.1 \pm 0.9$ & $4.9 \pm 1.1$ & $4.4 \pm 0.8^{\mathrm{a}}$ & $6.2 \pm 1.2$ & $410 \pm 14^{\mathrm{b}}$ & $380 \pm 12^{b}$ & $310 \pm 15^{b}$ & $314 \pm 14^{b}$ \\
\hline
\end{tabular}

Values are the means \pm SD of 4 independent experiments. ${ }^{\mathrm{a}} \mathrm{p}<0.05^{\mathrm{b}} \mathrm{p}<0.001$ as compared to normal platelet poor plasma (PPP).

BXPC 3 cells and by 59 and $45 \%$, respectively, in the presence of MCF7 cells $(\mathrm{p}<0.05)$.

In FXII-deficient plasma, the lag-time increased 2.7-fold for BXPC3 and 1.6-fold for MCF7 cells, compared to normal PPP $(\mathrm{p}<0.05)$. The peak and the MRI decreased by $26 \%$ and $55 \%$, respectively, in the presence of BXPC3 and by $55 \%$ and $81 \%$, respectively, in the presence of MCF7 cells ( $\mathrm{p}<0.05)$.

In FXI-deficient plasma, the lag-time increased 2.2-fold for BXPC3 and 1.9-fold for MCF7 cells compared to the experiment with normal PPP ( $>>0.05)$. The peak and the MRI decreased by 55 and $74 \%$, respectively, in the presence of BXPC3 and by 70 and $79 \%$, respectively, in the presence of MCF7 cells $(\mathrm{p}<0.05)$.

In FIX-deficient plasma, the lag-time increased 1.4-fold for BXPC3 and 2.5-fold for MCF7 cells compared to normal PPP $(\mathrm{p}<0.05)$. The peak and the MRI decreased by 78 and $94 \%$, respectively, in the presence of BXPC3 and by 92 and $96 \%$, respectively, in the presence of MCF7 cells $(\mathrm{p}<0.05)$.

In FVIII deficient-plasma, the lag-time was not modified by either BXPC3 or MCF7 cells, compared to normal PPP. However, the peak and the MRI decreased by 73 and $94 \%$, respectively, in the presence of BXPC 3 and by 84 and $96 \%$, respectively, in the presence of MCF7 cells $(\mathrm{p}<0.05)$.

In FX-, FV- and FII-deficient plasma, neither BXPC3 nor MCF7 cells induced any detectable thrombin generation. In protein C-deficient plasma, the peak and the MRI increased 1.3- and 1.6-fold, respectively, in the presence of BXPC3 and 1.9- and 4.7-fold, respectively, in the presence of MCF7 cells $(\mathrm{p}<0.05)$. The lag-time increased 0.7-fold for BXPC3 and 0.9-fold for MCF7 cells as compared to normal PPP $(\mathrm{p}<0.05)$.

Impact of tissue factor and procoagulant phospholipids on the procoagulant capacity of HUVECs, BXPC3 and MCF 7 cells. For control experiments, thrombin generation varied as a function of the presence of TF and procoagulant phospholipids (PPL) and as a function of TF concentration as showed in Table VI and Fig. 3. In the presence of optimal TF concentrations and procoagulant phospholipids (TF 5 pM/PPL $4 \mu \mathrm{M}$ ), BXPC3 and the MCF7 cells increased the MRI by 52 and $44 \%$, respectively, compared to the MRI obtained in the presence of TF ( $5 \mathrm{pM} / \mathrm{PPL} 4 \mu \mathrm{M})$ in PPP alone. Therefore, thrombin generation was higher in the presence of BXPC3 or MCF7 cells compared to the upper normal levels of normal plasma. When no TF and procoagulant phospholipids were added to the plasma with BXPC3, MCF7 or HUVECs, the MRI and peak were significantly lower compared to TF (5 pM/PPL $4 \mu \mathrm{M}$ ). Both BXPC3 and MCF7 cells and HUVECs induced significantly lower MRI with a reduction of 75 and $81 \%$, respectively, in the presence of BXPC3 and MCF7, and 90\% for HUVECs and the cellfree control (Table VI).

In plasma containing BXPC3 or MCF7 cells without addition of TF but with optimal concentrations of procoagulant phospholipids, the MRI significantly decreased compared to the same experiment in the presence of TF (5 pM/PPL $4 \mu \mathrm{M})$. Both BXPC3 and MCF7 cells induced significantly lower thrombin generation compared to that observed in the presence of TF ( $5 \mathrm{pM} / \mathrm{PPL} 4 \mu \mathrm{M})$ (Table VI). The MRI decreased by $31 \%$ and $77 \%$, respectively, in the presence of BXPC3 and MCF7, and 53 and $68 \%$ for HUVECs and the cell-free control, respectively.

In BXPC3 or MCF7 containing plasma at optimal TF concentrations but without any addition of procoagulant phospholipids, the MRI significantly decreased compared to the same experiment in the presence of TF (5 pM/PPL $4 \mu \mathrm{M})$. Both BXPC3 and MCF7 cells induced significantly less thrombin generation compared to that observed in the presence of TF ( $5 \mathrm{pM} / \mathrm{PPL} 4 \mu \mathrm{M})$ (Table VI). The MRI decreased 36 and $73 \%$, respectively, in the presence of BXPC3 and MCF7 cells and 92 and $81 \%$ for HUVECs and the cell-free control, respectively.

In BXPC3 or MCF7-containing plasma with optimal concentrations of procoagulant phospholipids but with a suboptimal concentration of TF, the MRI significantly decreased as compared to TF (5 pM/PPL $4 \mu \mathrm{M})$. The MRI decreased 23 and $35 \%$, respectively, in the presence of BXPC3 and MCF7 cells and 65 and $47 \%$ for HUVEC cells and the cell-free control, respectively (Table VI).

The impact of TF and procoagulant phospholipids on the MRI in plasma with BXPC3 and MCF7 cells is further detailed in Fig. 3. 


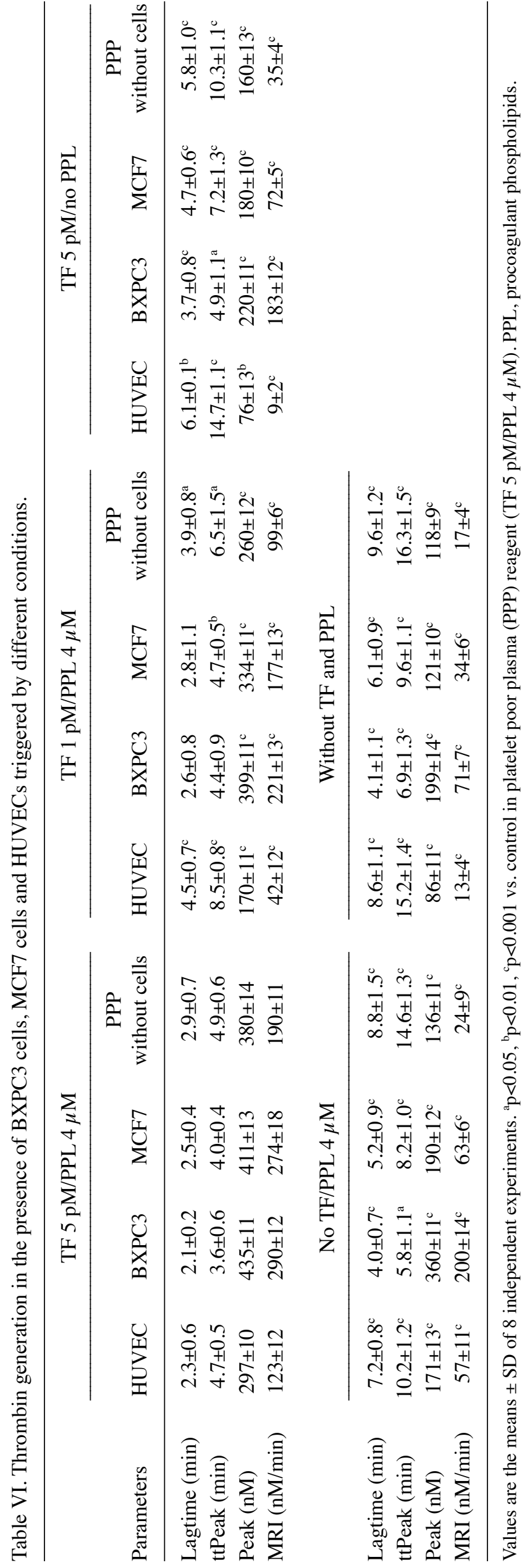

\section{Discussion}

The present study addressed three issues associated with cancer-induced hypercoagulability linked to thrombin generation: a) identification of the principal procoagulant elements expressed by cancer cells, b) evaluation of the relative roles of the TF-pathway and the intrinsic pathway in the thrombin generation process and c) contribution of the TF and procoagulant phospholipids present in the plasma microenvironment.

It is well established that cancer cells express TF, the major trigger of blood coagulation (28-30). We have previously demonstrated that BXPC3 pancreatic adenocarcinoma cells express significantly higher amounts of TF compared to MCF7 breast cancer cells as well as by normal human endothelial cells (HUVECs). The levels of TF expressed by cancer cells have been correlated with their effect on thrombin generation (21). In agreement, we herein show that the activity of TF (TFa) expressed by BXPC 3 cells was significantly higher than that expressed by MCF7 cells. The number of BXPC 3 or MCF7 cells tend to correlate with the TFa which was not the case for the HUVECs. The levels of asTF were also correlated with the number of BXPC3 or MCF7 cells. The TF isoform described as alternatively spliced TF (asTF) is expressed by both tumor cells and tumor tissues from cancer patients (31). However, the procoagulant activity of asTF has been debated (32-34). We find that asTF was expressed in abundant amounts by BXPC3 cells while lower expression levels were observed for MCF7 cells and HUVECs. The levels of asTF expressed by both types of cancer cells increased in parallel with the number of cells and were correlated with the release of TFa in the cellular environment. However, the experimental design of the present study does not allow the exploration of any potential relationship between the procoagulant activity of cancer cells and the levels of asTF.

The stimulation of thrombin generation by BXPC 3 and MCF7 cells was partially reversed by the presence of a monoclonal anti-TF antibody, which was not the case for HUVECs. These findings could be explained in, at least, two ways. First, the concentration of the anti-TF antibody may not be sufficiently high to completely neutralize TF activity. However, this hypothesis can be ruled out since the concentrations of the TF antibody was sufficiently high to completely inhibit thrombin generation in the presence of high levels of TF.

Second, thrombin generation could also be driven by alternative pathways independent of TF such as expression of cancer procoagulant activity thereby resulting in activation of the intrinsic system of blood coagulation. Both BXPC3 and MCF7 cells expressed $\mathrm{CP}$ and directly activate FX in a cysteine-dependent manner. However, the cancer procoagulant activity of MCF7 cells was approximately 4-fold higher compared to BXPC 3 cells. The capacity of cancer cells to activate the intrinsic pathway of blood coagulation was determined using CTI, which selectively inhibits FXIIa $(35,36)$. Inhibition of FXIIa resulted in a significant prolongation of the initiation phase of thrombin generation triggered by both BXPC3 and MCF7 cells. This experiment clearly shows that both types of cancer cells could induce thrombin generation via activation of FXII, with MCF7 cells being more potent in this regard.

We also evaluated the role of each of the different clotting factors on thrombin generation triggered by cancer cells. The 
results show that FVII was of major importance for the initiation and propagation phase of thrombin generation induced by BXPC 3 cells. The binding of factor VII to TF is considered to be the principal pathway of $\mathrm{FX}$ activation during normal coagulation (14). Thrombin generation triggered by the BXPC3 cells in FVII-deficient plasma thrombin could not be sustained, in contrast to thrombin generation triggered by MCF7 cells, in full agreement with the capacity of MCF7 to trigger thrombin generation via an alternative pathway through activation of FXII. This was confirmed by experiments with FXII-deficient plasma, where MCF7 mediated thrombin generation was almost completely abrogated. FXII is activated following prekallikrein and high molecular weight kininogen activation. FVII and thrombin are also among the activators of FXII. In our experimental conditions, in the presence of either BXPC3 or MCF7 cells, the levels of both FVII and FII were normal. Therefore, we assume that when coagulation was triggered by MCF7 cells, the deficiency of FXII interrupted the activation pathway leading to FXIa generation and to intrinsic tenase formation. The experiments with FXI-deficient plasma further supported the importance of the intrinsic pathway activation by the MCF7 cells. In contrast, for BXPC3 cells, the intrinsic pathway was clearly secondary compared to TF. Thrombin generation triggered by both BXPC3 or MCF7 cells was abrogated in FVIII- or FIX-deficient plasma confirming that the formation of the intrinsic tenase is of major importance in the amplification of the propagation phase of thrombin generation in the presence of cancer cells. In addition, this experiment demonstrated the weak procoagulant efficiency of the CP. In plasma deficient of FX, FV or FII neither BXPC3 nor MCF7 cells, were able to promote thrombin generation. Thus, the possibility of a 'prothrombinase-like' or a 'thrombin like' activity expressed by the cancer cells was eliminated. Finally, the experiments with protein C-deficient plasma showed that the down-regulation of thrombin generation by the protein $\mathrm{C}$ pathway was significantly more important for MCF7 cells as compared to BXPC3 cells.

The last part of the study revealed that the procoagulant activity of cancer cells was necessary, but not sufficient, to induce hypercoagulability; i.e. thrombin generation higher than the upper normal limit, as defined by the addition of physiologically relevant concentrations of TF and procoagulant phospholipid to normal plasma $(37,38)$. Subsequently, we determined if the procoagulant efficiency of cancer cells could be amplified by procoagulant elements in the plasma. In plasma enriched with an optimal concentration of procoagulant phospholipids, the presence of BXPC3 cells resulted in near normalization of thrombin generation. In the presence of MCF7 cells and procoagulant phospholipids, thrombin generation remained significantly lower compared to the normal levels under optimal conditions. We also examined the impact of exogenous TF (without any exogenous addition of procoagulant phospholipids) on thrombin generation triggered by cancer cells. We found that procoagulant phospholipids are essential for the enhancement of thrombin generation induced by cancer cells even if the microenvironment is rich in TF. Importantly, in contrast to cancer cells, normal endothelial cells (HUVECs) had no effect on thrombin generation.

We finally studied the impact of the joint presence of TF and procoagulant phospholipids on thrombin generation triggered by cancer cells. This experiment showed that hypercoagulability induced by cancer cells is the resultant of the combination of the procoagulant properties of cancer cells in addition to the procoagulant elements of the plasma microenvironment which consist of a) an optimum concentration of procoagulant phospholipids and b) TF at concentrations higher than $1 \mathrm{pM}$.

In conclusion, we herein report that BXPC3 and MCF7 cancer cells trigger and enhance thrombin generation by both the TF-pathway and the intrinsic pathway. Although the TF-pathway is dominant, the intrinsic system should not be neglected since the relative impact of the two pathways varies as a function of cancer cell type. The formation of intrinsic tenase and prothrombinase plays a major role for thrombin generation triggered by cancer cells. To the best of our knowledge, the present study reports for the first time that the inherent procoagulant properties of cancer cells are necessary, but not sufficient, to induce hypercoagulability since procoagulant elements of the microenvironment, in particular TF and phospholipids, are necessary elements for cancer-induced hypercoagulability.

\section{Acknowledgements}

The authors wish to acknowledge Ms. Hayat Mokrani and Mr. Matthieu Gusse, for their skillful technical assistance. The study was supported by an unrestricted grant from Stago France and by the 'Association de Recherche sur la Thrombose et l'Evaluation de son Risque'.

\section{References}

1. Trousseau A: Clinique Médicale de l'Hôtel-Dieu de Paris. Vol. 3 , 2nd edition. JB Baillière, Paris, pp654-712, 1865.

2. Falanga A, Russo L and Milesi V: The coagulopathy of cancer. Curr Opin Hematol 21: 423-429, 2014

3. Khorana AA, Francis CW, Culakova E, Kuderer NM and Lyman GH: Thromboembolism is a leading cause of death in cancer patients receiving outpatient chemotherapy. J Thromb Haemost 5: 632-634, 2007.

4. Chew HK, Wun T, Harvey D, Zhou H and White RH: Incidence of venous thromboembolism and its effect on survival among patients with common cancers. Arch Intern Med 166: 458-464, 2006.

5. Prandoni P, Falanga A and Piccioli A: Cancer and venous thromboembolism. Lancet Oncol 6: 401-410, 2005.

6. Lee AY and Levine MN: Venous thromboembolism and cancer: Risks and outcomes. Circulation 107 (Suppl 1): I17-I21, 2003.

7. Caine GJ, Stonelake PS, Lip GY and Kehoe ST: The hypercoagulable state of malignancy: Pathogenesis and current debate. Neoplasia 4: 465-473, 2002.

8. De Cicco M: The prothrombotic state in cancer: Pathogenic mechanisms. Crit Rev Oncol Hematol 50: 187-196, 2004.

9. Roberts HR, Hoffman M and Monroe DM: A cell-based model of thrombin generation. Semin Thromb Hemost 32 (Suppl 1): 32-38, 2006.

10. Amin C, Mackman N and Key NS: Microparticles and cancer. Pathophysiol Haemost Thromb 36: 177-183, 2008.

11. Davila M, Amirkhosravi A, Coll E, Desai H, Robles L, Colon J, Baker $\mathrm{CH}$ and Francis JL: Tissue factor-bearing microparticles derived from tumor cells: Impact on coagulation activation. J Thromb Haemost 6: 1517-1524, 2008.

12. Rauch $U$ and Nemerson Y: Circulating tissue factor and thrombosis. Curr Opin Hematol 7: 273-277, 2000.

13. Butenas S, Orfeo T and Mann KG: Tissue factor activity and function in blood coagulation. Thromb Res 122 (Suppl 1): S42-S46, 2008.

14. Mackman N: The role of tissue factor and factor VIIa in hemostasis. Anesth Analg 108: 1447-1452, 2009. 
15. Mutch NJ: Emerging roles for factor XII in vivo. J Thromb Haemost 9: 1355-1358, 2011.

16. Müller F and Renné T: Novel roles for factor XII-driven plasma contact activation system. Curr Opin Hematol 15: 516-521, 2008.

17. Thomassen MC, Heinzmann AC, Herfs L, Hartmann R. Dockal M, Scheiflinger F, Hackeng TM and Rosing J: Tissue factor-independent inhibition of thrombin generation by tissue factor pathway inhibitor- $\alpha$. J Thromb Haemost 13: 92-100, 2015.

18. Nickel KF, Ronquist G, Langer F, Labberton L, Fuchs TA, Bokemeyer C, Sauter G, Graefen M, Mackman N, Stavrou EX, et al: The polyphosphate-factor XII pathway drives coagulation in prostate cancer-associated thrombosis. Blood 126: 1379-1389, 2015.

19. Gordon SG and Mielicki WP: Cancer procoagulant: A factor X activator, tumor marker and grow th factor from malignant tissue. Blood Coagul Fibrinolysis 8: 73-86, 1997.

20. Donati MB, Gambacorti-Passerini C, Casali B, Falanga A, Vannotti P, Fossati G, Semeraro N and Gordon SG: Cancer procoagulant in human tumor cells: Evidence from melanoma patients. Cancer Res 46: 6471-6474, 1986.

21. Gerotziafas GT, Galea V, Mbemba E, Khaterchi A, Sassi M, Baccouche H, Prengel C, van Dreden P, Hatmi M, Bernaudin JF, et al: Tissue factor over-expression by human pancreatic cancer cells BXPC3 is related to higher prothrombotic potential as compared to breast cancer cells MCF7. Thromb Res 129: 779-786, 2012

22. Marchetti M, Diani E, ten Cate $\mathrm{H}$ and Falanga A: Characterization of the thrombin generation potential of leukemic and solid tumor cells by calibrated automated thrombography. Haematologica 97: 1173-1180, 2012.

23. Van Dreden P, Rousseau A, Savoure A, Lenormand B, Fontaine S and Vasse M: Plasma thrombomodulin activity, tissue factor activity and high levels of circulating procoagulant phospholipid as prognostic factors for acute myocardial infarction. Blood Coagul Fibrinolysis 20: 635-641, 2009.

24. Rousseau A, Favier R and Van Dreden P: Elevated circulating soluble thrombomodulin activity, tissue factor activity and circulating procoagulant phospholipids: New and useful markers for pre-eclampsia? Eur J Obstet Gynecol Reprod Biol 146: 46-49, 2009.

25. Schneider P, Van Dreden P, Rousseau A, Kassim Y, Legrand E, Vannier JP and Vasse M: Increased levels of tissue factor activity and procoagulant phospholipids during treatment of children with acute lymphoblastic leukaemia. Br J Haematol 148: 582-592, 2010.

26. Hemker HC, Giesen P, AlDieri R, Regnault V, de Smed E, Wagenvoord $\mathrm{R}$, Lecompte $\mathrm{T}$ and Béguin $\mathrm{S}$ : The calibrated automated thrombogram (CAT): A universal routine test for hyper- and hypocoagulability. Pathophysiol Haemost Thromb 32: $249-253,2002$
27. Gerotziafas GT, Depasse F, Busson J, Leflem L, Elalamy I and Samama MM: Towards a standardization of thrombin generation assessment: The influence of tissue factor, platelets and phospholipids concentration on the normal values of Thrombogram-Thrombinoscope assay. Thromb J 3: 16, 2005.

28. Tilley RE, Holscher T, Belani R, Nieva J and Mackman N: Tissue factor activity is increased in a combined platelet and microparticle sample from cancer patients. Thromb Res 122: 604-609, 2008

29. Key NS, Chantrathammachart P, Moody PW and Chang JY: Membrane microparticles in VTE and cancer. Thromb Res 125 (Suppl 2): S80-S83, 2010.

30. Zwicker JI, Liebman HA, Neuberg D, Lacroix R, Bauer KA, Furie BC and Furie B: Tumor-derived tissue factor-bearing microparticles are associated with venous thromboembolic events in malignancy. Clin Cancer Res 15: 6830-6840, 2009.

31. Bogdanov VY, Kirk RI, Miller C, Hathcock JJ, Vele S, Gazdoiu M, Nemerson Y and Taubman MB: Identification and characterization of murine alternatively spliced tissue factor. J Thromb Haemost 4: 158-167, 2006.

32. Böing AN, Hau CM, Sturk A and Nieuwland R: Human alternatively spliced tissue factor is not secreted and does not trigger coagulation. J Thromb Haemost 7: 1423-1426, 2009.

33. Szotowski B, Antoniak S and Rauch U: Alternatively spliced tissue factor: A previously unknown piece in the puzzle of hemostasis. Trends Cardiovasc Med 16: 177-182, 2006.

34. Censarek P, Bobbe A, Grandoch M, Schrör K and Weber AA: Alternatively spliced human tissue factor (asHTF) is not procoagulant. Thromb Haemost 97: 11-14, 2007.

35. Spronk HM, Dielis AW, Panova-Noeva M, van Oerle R, Govers-Riemslag JW, Hamulyák K, Falanga A and Cate HT: Monitoring thrombin generation: Is addition of corn trypsin inhibitor needed? Thromb Haemost 101: 1156-1162, 2009.

36. van Veen JJ, Gatt A, Cooper PC, Kitchen S, Bowyer AE and Makris M: Corn trypsin inhibitor in fluorogenic thrombingeneration measurements is only necessary at low tissue factor concentrations and influences the relationship between factor VIII coagulant activity and thrombogram parameters. Blood Coagul Fibrinolysis 19: 183-189, 2008.

37. Parhami-Seren B, Butenas S, Krudysz-Amblo J and Mann KG Immunologic quantification of tissue factors. J Thromb Haemost 4: 1747-1755, 2006.

38. Berntorp E and Salvagno GL: Standardization and clinical utility of thrombin-generation assays. Semin Thromb Hemost 34: $670-682,2008$ 